\title{
CD44 activation state regulated by the CD44v10 isoform determines breast cancer proliferation
}

\author{
QIAN GUO, YIWEN LIU, YIQING HE, YAN DU, GUOLIANG ZHANG, CUIXIA YANG and FENG GAO \\ Department of Clinical Laboratory and Molecular Biology, Shanghai Jiao Tong University \\ Affiliated Sixth People's Hospital, Shanghai 200233, P.R. China
}

Received September 22, 2020; Accepted January 14, 2021

DOI: $10.3892 /$ or.2021.7958

\begin{abstract}
The cell surface glycoprotein CD44 displays different active statuses; however, it remains unknown whether the activation process of CD44 is critical for tumor development and progression. The aim of the present study was to investigate whether breast cancer $(\mathrm{BCa})$ cells with different activation states of CD44 show similar or distinct functional characteristics and to further examine the mechanisms regulating CD44 activities. A feature for the 'activated' state of CD44 is that it can bind to its principal ligand hyaluronan (HA). The binding of CD44 with HA is usually influenced by CD44 alternative splicing, resulting in multiple CD44 isoforms that determine CD44 activities. Flow cytometry was used to sort BCa cell subsets based on CD44-HA binding abilities $\left(\mathrm{HA}^{-/ \text {low }}\right.$ vs. HA $\left.{ }^{\text {high }}\right)$. Subsequently, cell proliferation and colony formation assays were performed in vitro, and CD44 expression patterns were analyzed via western blotting. The results demonstrated that the CD44 variant isoform 10 (CD44v10) was highly expressed in a $\mathrm{HA}^{-/ \text {low }}$ binding subset of $\mathrm{BCa}$ cells, which exhibited a significantly higher proliferation capacity compared with the $\mathrm{HA}^{\text {high }}$ binding subpopulation. Knockdown of CD44v10 isoform in $\mathrm{HA}^{-/ \text {low }}$ binding subpopulation induced an increase in HA binding ability and markedly inhibited proliferation. Furthermore, the mechanistic analysis identified that CD44v10 facilitated cell proliferation via activation of ERK/p38 MAPK and AKT/mTOR signaling. Moreover, the knockdown of CD44v10 expression downregulated the phosphorylation of ERK, AKT and mTOR, while no alteration was observed in p38 phosphorylation. Collectively, the present
\end{abstract}

Correspondence to: Professor Feng Gao and Professor Cuixia Yang, Department of Clinical Laboratory and Molecular Biology, Shanghai Jiao Tong University Affiliated Sixth People's Hospital, 600 Yishan Street, Scientific Research Building, Room 1010, Shanghai 200233, P.R. China

E-mail: gao3507@126.com

E-mail:dr.steven@163.com

Key words: breast cancer, CD44 activation state, CD44 variant isoform 10 , hyaluronan, proliferation study identified a subset of fast-growing BCa cells characterized by CD44v10 expression, which may serve as a specific therapeutic target for $\mathrm{BCa}$.

\section{Introduction}

Breast cancer $(\mathrm{BCa})$ remains the most common type of malignant tumor among women, with $11.6 \%$ for incidence and $6.6 \%$ for mortality worldwide in 2018 (1). Clinically, breast tumors often display intra-tumoral heterogeneity. Multiple cell subpopulations within a single tumor may show diverse phenotypes, such as different cell surface markers, growth rates, metastasis and therapeutic responses that eventually drive cancer progression (2). There is currently a lack of approaches for identifying more aggressive subpopulations in a tumor mass, which makes it difficult to monitor cancer progression and response to treatment. Thus, it is of urgent importance to examine novel targets for the valuable diagnosis of $\mathrm{BCa}$.

CD44 is a family of cell surface glycoproteins ubiquitously expressed by various tumors, especially in $\mathrm{BCa}$ (3). CD44 participates in cell adhesion and migration, lymphocyte homing and activation, and abnormal behaviors of tumor cells $(4,5)$. Hyaluronan (HA), the principal ligand for CD44, is a major extracellular matrix component accumulated in stromal and tumor cells (6). Studies have reported that HA acts by binding to CD44 to modulate various fundamental and pathological processes, including cell-cell adhesion, cell proliferation, cancer migration and invasion (7-9). However, not all CD44-expressing cells can constitutively bind HA; only activated CD44 binds and internalizes HA. Thus, the cellular behaviors induced by CD44-HA binding are cell-specific and strongly depend on the activation states of CD44 (10). As previously reported, CD44 participates in three different contexts in relation to its binding capacities with HA: Inactive, constitutively active and inducible active (does not bind to HA unless activated by appropriate stimuli) $(11,12)$. Although numerous studies have highlighted the association of CD44 expression with breast malignancies, it remains unknown whether an activation process of CD44 is critical for $\mathrm{BCa}$ development and progression (13-15).

Previous studies have revealed that CD44 activation is a complex and dynamic process, as the ability of CD44 to engage $\mathrm{HA}$ is highly regulated $(16,17)$. In humans, the full-length CD44 gene consists of 19 exons that have molecular masses 
ranging from $80-250 \mathrm{kDa}(18)$. The shortest $\mathrm{CD} 44$ standard isoform (CD44s) includes only constitutive exons, while the CD44 variant isoforms $(\mathrm{CD} 44 \mathrm{v})$ undergo alternative splicing and contain $\geq 1$ variable exons (19). Although all CD44 molecules share a common HA-binding domain, their affinities for surface-bound hyaluronate are different, which suggests that the structural heterogeneity of CD44 alternative splicing may be responsible for modulating CD44 activation (20). Early observations using melanoma models demonstrated that CD44s bound to HA more efficiently compared with CD44v8-v10 (21). At the same time, another study suggested that the splice variant of CD44v4-v7 confers stronger HA-binding properties compared with $\mathrm{CD} 44 \mathrm{~s}$ in rat pancreatic carcinoma cell lines (22). These different results indicated that CD44 isoforms may have distinct roles in its binding ability with HA. However, the effect of CD44 isoforms on CD44 activation in $\mathrm{BCa}$ is poorly understood. Although there are still some controversies, it is considered that alternative splicing determines CD44 activities. Moreover, accumulating evidence has suggested that CD44 splice isoforms contribute to cellular and functional behaviors by mediating specific signaling pathways (23). CD44v was reported to stimulate MAPK activation and to promote cell proliferation (24), while CD44s was suggested to trigger the PI3K/AKT/mTOR signaling cascade and contribute to tumor cell escape from drug-induced cell death (25). However, whether the different CD44v isoforms share common signaling pathways to regulate the biologic function is yet to be elucidated.

The present study aimed to investigate whether CD44 activation is critical requirement for $\mathrm{BCa}$ cells proliferation and to further examine which CD44 isoform determines CD44 activities. Firstly, $\mathrm{HA}^{-/ 10 w}$ and $\mathrm{HA}^{\text {high }}$ subpopulations were isolated using FACS technique, and cell proliferation assays in vitro were applied to assess whether the two subsets exhibited different proliferative capacity. Then, a panel of small interfering (si)RNAs targeting each CD44v exon region were employed to identify which $C D 44 \mathrm{v}$ isoform was associated with CD44 activities and cells proliferation. Furthermore, the current study investigated the underlying mechanisms by studying the proliferation-related ERK/p38 MAPK and AKT/mTOR signal pathway. These findings identified a subset of fast-growing BCa cells characterized by CD44v10 expression, which may serve as a promising therapeutic target for BCa.

\section{Materials and methods}

Cell lines and culture. Human BCa cell lines (MCF-7, T-47D, BT-549 and MDA-MB-231) were obtained from the Cell Bank of the Type Culture Collection of the Chinese Academy of Sciences. MCF-7 cells were cultured in MEM (Gibco; Thermo Fisher Scientific, Inc.), T-47D and BT-549 cells were cultured in RPMI-1640 medium (Gibco; Thermo Fisher Scientific, Inc.) and MDA-MB-231 cells were cultured in high-glucose DMEM (Gibco; Thermo Fisher Scientific, Inc.). All cell lines were maintained at a temperature of $37^{\circ} \mathrm{C}$ in humidified air with $5 \% \mathrm{CO}_{2}$. All cell culture media were supplemented with 10\% FBS (Bovogen Biologicals Pty Ltd.), $100 \mathrm{U} / \mathrm{ml}$ penicillin and $100 \mathrm{mg} / \mathrm{ml}$ streptomycin. In addition, all cells were grown to $80 \%$ confluency for the experiments.
Isolation of $H A$ high and $H A^{-l l o w}$ subpopulations by FACS. Fluorescein-labeled HA (fl-HA; Merck KGaA) binding was used to determine the CD44 activation state. In total, $\sim 5.0 \times 10^{7}$ cells in supplemented Hank's balanced salt solution (HBSS) were incubated on ice with a working concentration of $40 \mu \mathrm{g} / \mathrm{ml} \mathrm{fl}-\mathrm{HA}$ for $1 \mathrm{~h}$, as previously described (26). Unbounded fl-HA was removed via centrifugation (682 x g for $5 \mathrm{~min}$ at room temperature) two times with HBSS. After resuspended in the HBSS, the cells were filtered through cell strainers and analyzed via CytoFLEX flow cytometer (Beckman-Coulter, Inc.). Non-viable cells were excluded using 7-amino-actinomycin D dye (staining for $15 \mathrm{~min}$ at room temperature). Fl-HA-bound cells were sorted using gates set to a $10 \%$ threshold on a histogram profile. Cells were sorted into $\mathrm{HA}^{\text {high }}$ and $\mathrm{HA}^{- \text {llow }}$ subpopulations based on differential binding to HA (10\% maximum and minimum signal selection), and collected for further in vitro analyses. In preparation for $\mathrm{HA}$ binding analysis, a $\mathrm{HA}^{-/ \mathrm{low}}$ single-cell suspension $\left(10^{6} \mathrm{cells} / \mathrm{ml}\right)$ was incubated with fl-HA or isotype control antibody for $1 \mathrm{~h}$ on ice. After washing three times, the HA binding profile was subsequently analyzed using a flow cytometer (MoFlo Astrios EQ; Beckman-Coulter, Inc.).

Cell Counting Kit (CCK-8) assay. The cell viability was measured using a CCK-8 assay (Dojindo Molecular Technologies, Inc.) according to the manufacturer's protocol. Briefly, cells in the logarithmic growth phase were seeded in triplicate onto 96 -well plates at a density of $3.0 \times 10^{3}$ cells per well. Cells were then incubated for $0,1,2,3$ and 4 days, after which the complete medium of each well was replaced by $10 \mu \mathrm{l}$ CCK-8 solution supplemented with $90 \mu \mathrm{l}$ serum-free medium and incubated at $37^{\circ} \mathrm{C}$ for additional $2 \mathrm{~h}$. The absorbance was then measured at $450 \mathrm{~nm}$ using a microplate absorbance reader (Bio-Rad Laboratories, Inc.). In preparation for rescue experiments, $\mathrm{HA}^{-/ \text {low }}$ cells were incubated $\left(37^{\circ} \mathrm{C}\right)$ with anti-CD44 monoclonal antibody or normal $\operatorname{IgG}(10 \mu \mathrm{g} / \mathrm{ml}$; Invitrogen) for $48 \mathrm{~h}$ after transfected with CD44v10 siRNA, and measured using the CCK- 8 assay.

5-Ethynyl-20- deoxyuridine (EdU) assay. Cell proliferation was analyzed using EdU assays with a Cell-Light EdU DNA Cell Proliferation kit (Beyotime Institute of Biotechnology). Sorted $\mathrm{HA}^{\text {high }}$ and $\mathrm{HA}^{-/ \mathrm{low}}$ cells were resuspended for cell density adjustment at $1 \times 10^{5} / \mathrm{ml}$. A total of $100 \mu 1$ suspension was seeded into each well of the 96-well plates. After incubation overnight, $10 \mathrm{mM} \mathrm{EdU}$ was added and incubated at $37^{\circ} \mathrm{C}$ for another $2 \mathrm{~h}$. Cells were then stained with azide ( $30 \mathrm{~min}$, for proliferating cells) and Hoechst 33342 (10 min, for all cells) at room temperature. Images were captured using a fluorescence microscope (Nikon Corporation, magnification, $\mathrm{x} 100$ ). The percentage of proliferating cells was calculated using ImageJ V1.50 software (National Institutes of Health).

Plate colony formation assay. A total of 500 viable cells per well were plated into 6-well culture plates. All plates were then incubated for 14 days at $37^{\circ} \mathrm{C}$ to allow colony formation. The cells were washed twice with PBS and fixed with $4 \%$ paraformaldehyde for $30 \mathrm{~min}$ at room temperature, followed by staining with $0.1 \%$ crystal violet (BaSO Biotech Co., Ltd.) for $30 \mathrm{~min}$ at room temperature. After rinsing three times, the 
stained colonies were imaged and the number of colonies was counted by the naked eye. In total, three parallel wells were set for each group.

Western blot analysis. Total proteins were extracted with RIPA lysis buffer (Beyotime Institute of Biotechnology) supplemented with protease and phosphatase inhibitors (Beyotime Institute of Biotechnology). Protein concentration was quantified using a BCA Protein Assay kit (Thermo Fisher Scientific, Inc.). Proteins ( $\sim 20 \mu \mathrm{g} /$ lane) were separated by $8 \%$ SDS-PAGE and then transferred to PVDF membranes (Merck Millipore). The membranes were blocked with $5 \%$ skimmed milk in $0.1 \%$ TBS-Tween-20 at room temperature for $1 \mathrm{~h}$ and incubated with following primary antibodies overnight at $4^{\circ} \mathrm{C}$ : Pan-CD44 (dilution 1:1,000; Abcam; cat. no. ab189524), CD44v10 (dilution 1:1,000; Sigma-Aldrich; Merck KGaA; cat. no. AB2082), phosphorylated (p)-ERK1/2 [dilution 1:2,000; Cell Signaling Technology, Inc. (CST); cat. no. 4370], ERK1/2 (dilution 1:1,000; CST; cat. no. 4695), p-p38 (dilution 1:1,000; CST; cat. no. 4511), p38 (dilution 1:1,000; CST; cat. no. 9212), p-AKT (dilution 1:2,000; CST; cat. no. 4060), AKT (dilution 1:1,000; CST; cat. no. 4691), p-mTOR (dilution 1:1,000; CST; cat. no. 5536) and mTOR (dilution 1:1,000; CST; cat. no. 2983), GAPDH (dilution 1:1,000; Lianke Biotech Co., Ltd.; cat. no. Mab5465). On the following day, membranes were incubated with horseradish peroxidase-conjugated secondary antibody goat anti-rabbit IgG (dilution 1:5,000; Lianke Biotech Co., Ltd.; cat. no. 70-GAR0072) or goat anti-mouse IgG (dilution 1:5,000; Lianke Biotech Co., Ltd.; cat. no. 70-GAM0072) for $1 \mathrm{~h}$ at room temperature. Subsequently, an image of the protein band was captured using the ChemiDoc ${ }^{\mathrm{TM}} \mathrm{MP}$ imaging system (Bio-Rad Laboratories, Inc.) using the enhanced plus chemiluminescence reagent (EMD Millipore; cat. no. WBKL-S0100). The band densities were semi-quantitated using ImageJ V1.50 software (National Institutes of Health).

siRNA for CD44 variants. The expression of CD44 variants was knocked down using corresponding siRNAs. A series of siRNA oligonucleotides including sicontrol, siCD44v3, siCD44v4, siCD44v5, siCD44v6, siCD44v7, siCD44v8, siCD44v9 and siCD44v10 were designed and synthesized by Guangzhou RiboBio Co., Ltd. The CD44v2 exon was excluded in current study due to its considerably low expression in $\mathrm{BCa}$ cells (27). The siRNA oligonucleotides are listed in Table SI. The MDA-MB-231 and BT-549 cells were separately seeded in 6-well plates at $3 \times 10^{5} /$ well and transfected with siRNA for $48 \mathrm{~h}$ at $37^{\circ} \mathrm{C}$ using riboFECT ${ }^{\mathrm{TM}}$ (Guangzhou RiboBio Co., Ltd.), according to the manufacturer's protocol, and $50 \mathrm{nM}$ siRNAs. Reverse transcription-quantitative (RT-q)PCR was performed to verify the transfection efficacy after $48 \mathrm{~h}$, and cells were either used for in vitro experiments or lysed for western blot analysis.

$R T-q P C R$. Total RNA was extracted from cultured cells using RNAiso Plus (Takara Bio, Inc.), according to the manufacturer's instructions. The RNA concentration was measured using NanoDrop system (Thermo Fisher Scientific, Inc.). Then, $1 \mu \mathrm{g}$ mRNA was reverse transcribed using the PrimeScript ${ }^{\mathrm{TM}}$ RT Reagent kit with gDNA Eraser (Takara Bio, Inc.). qPCR assays were performed with SYBR-Green mix (Takara Bio, Inc.) according to the manufacturer's protocol. The sequences of primers for CD44 exon-specific qPCR used in the study are listed in Table SII, which were those reported by Hu et al (28). The qPCR conditions included: Initial denaturation at $95^{\circ} \mathrm{C}$ for $30 \mathrm{sec}$, followed by 40 cycles of denaturation at $95^{\circ} \mathrm{C}$ for $5 \mathrm{sec}$ annealing and extension at $60^{\circ} \mathrm{C}$ for $34 \mathrm{sec}$. All RT-qPCR values of each gene were normalized against that of GAPDH. The relative gene expression was calculated using the $2^{-\Delta \Delta \mathrm{Cq}}$ method (29).

Statistical analysis. Statistical analysis was performed using GraphPad Prism 8.0.2 (GraphPad Software, Inc.). Data are presented the as mean \pm SD. The statistically significant of differences between the two groups were determined with an unpaired Student's t-test. $\mathrm{P}<0.05$ was considered to indicate a statistically significant difference.

\section{Results}

Sorting of BCa cells based on HA binding reveals subpopulations with distinct proliferative capacities. To gain insights into the distinct functions of CD44 activities, fl-HA was used to probe CD44-HA binding abilities. $\mathrm{HA}^{\text {high }}$ and $\mathrm{HA}^{- \text {llow }}$ subpopulations were isolated from two less malignant $\mathrm{BCa}$ cell lines (MCF-7 and T-47D) and two more malignant cells (MDA-MB-231 and BT-549) using the FACS technique (Fig. S1). A subsequent CCK- 8 assay demonstrated that the $\mathrm{HA}^{- \text {-low }}$ subpopulations were significantly more proliferative compared with the $\mathrm{HA}^{\text {high }}$ subpopulations in all investigated BCa cell lines (Fig. 1A). The basal-like cell lines MDA-MB-231 and BT-549 were selected for the following experiments as these are malignant triple-negative $\mathrm{BCa}$ cells that exhibit more aggressive properties. Consistent with the CCK-8 results, the EdU incorporation assay and plate colony formation assay demonstrated that the proliferation of $\mathrm{HA}^{- \text {llow }}$ subpopulations was higher compared with that of $\mathrm{HA}^{\text {high }}$ subpopulations in both MDA-MB-231 and BT-549 cells (Fig. 1B and C).

CD44v10 isoform is highly expressed in $H A^{- \text {llow }}$ binding subpopulation. Based on the aforementioned finding that $\mathrm{HA}^{- \text {-low }}$ subsets grew faster than $\mathrm{HA}^{\text {high }}$ cells, it was next investigated whether CD44 expression patterns were associated with CD44 activities. First, western blotting with pan-CD44 antibody revealed that the expression levels of CD44s in $\mathrm{HA}^{\text {high }}$ and $\mathrm{HA}^{- \text {/low }}$ subsets sorted from MDA-MB-231 and BT-549 cells were comparable, while the CD44v in $\mathrm{HA}^{-/ / \text {low }}$ cells was significantly higher compared with that in the HA ${ }^{\text {high }}$ cells (Fig. 2A). Notably, an $\sim 120 \mathrm{kDa}$ intense band was detected in the $\mathrm{HA}^{- \text {-low }}$ subpopulations but was weaker in the $\mathrm{HA}^{\text {high }}$ cells (Fig. 2A).

Next, to further identify which CD44v isoform corresponding to the $120 \mathrm{kDa}$ protein determines the CD44 activation state, a panel of siRNAs targeting each CD44v exon region was designed and synthesized. The expression levels of each CD44v mRNA were downregulated after siRNA transfection (Fig. S2). It was noted that the band at $120 \mathrm{kDa}$ was significantly decreased in MDA-MB-231 unsorted parental cells only after CD44v10 siRNA transfection (Fig. 2B) and was verified in $\mathrm{HA}^{-/ \mathrm{low}}$ subpopulations of both MDA-MB-231 and BT-549 cells (Fig. 2C). As confirmed previously, the $120 \mathrm{kDa}$ 
A
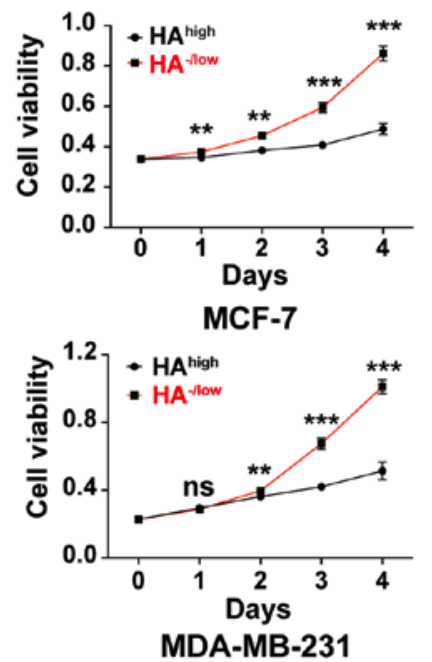

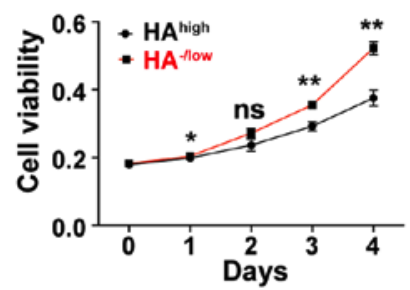

T-47D

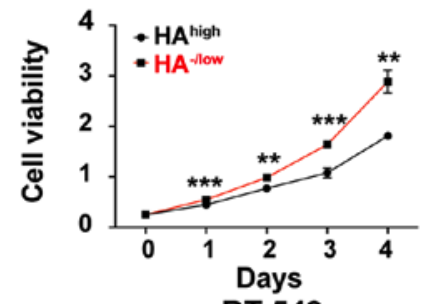

BT-549

B
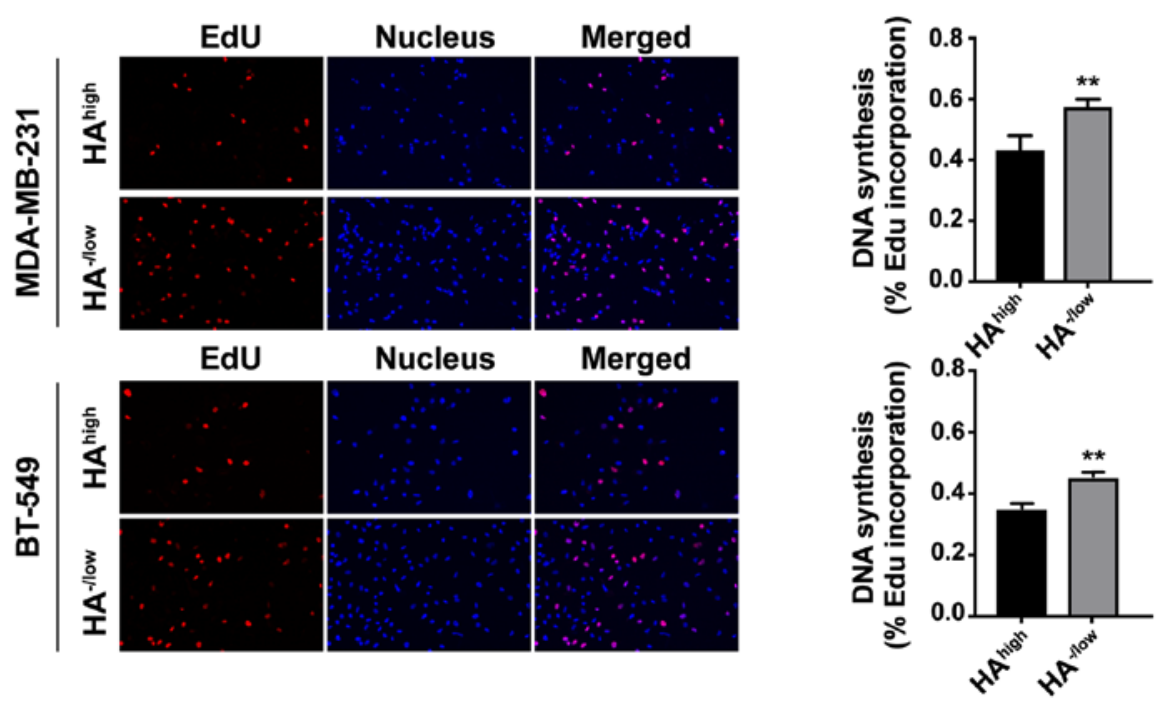

C

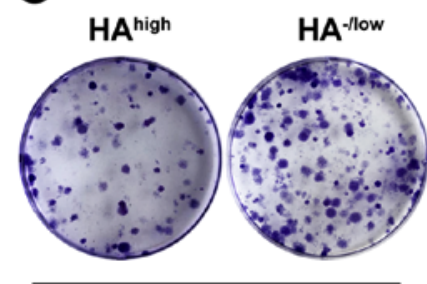

MDA-MB-231

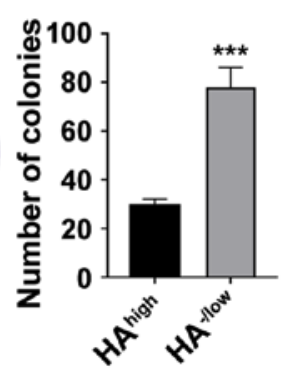

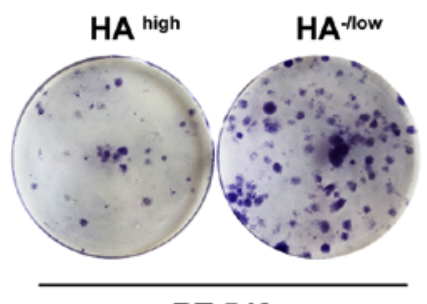

BT-549

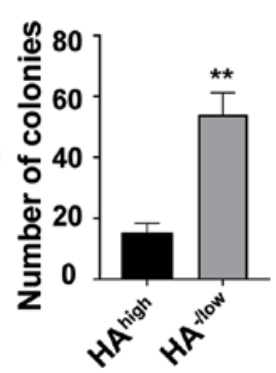

Figure 1. $\mathrm{HA}^{- \text {/low }}$ subpopulation exhibits a significantly higher capacity of proliferation compared with the HA ${ }^{\text {high }}$ subset. (A) Proliferation of FACS sorted HA ${ }^{\text {high }}$ binding and $\mathrm{HA}^{-/ \mathrm{low}}$ binding cells from MCF-7, T-47D, MDA-MB-231 and BT-549 BCa cells was assessed using a Cell Counting Kit-8 assay on the indicated days. (B) DNA synthesis was detected using EdU incorporation of sorted $\mathrm{HA}^{\text {high }}$ and $\mathrm{HA}^{-/ \mathrm{low}}$ cancer cells in MDA-MB-231 and BT-549. Cells were fluorescently stained with EdU (red), nuclei were stained with Hoechst 3342 (blue). Micrographs represent $\geq 3$ experiments (magnification, x100). Quantitative EdU assay data are presented as the mean \pm SD of three experiments. (C) Plate colony formation capability of $\mathrm{HA}^{\text {high }}$ and HA ${ }^{-/ l o w}$ cells derived from MDA-MB-231 and BT-549 cells. Cells were cultured for 14 days, and the number of colonies $>10 \mathrm{~mm}^{2}$ in each well was quantified. Unpaired Student's t-tests were used to analyze the data. Data are presented as the mean $\pm \mathrm{SD}$ of three separate experiments. ${ }^{*} \mathrm{P}<0.05,{ }^{* *} \mathrm{P}<0.01,{ }^{* * * *} \mathrm{P}<0.001$ vs. HA ${ }^{\text {high }}$ cells. ns, no significance; EdU, 5-ethynyl-2'-deoxyuridine; HA, hyaluronan.

corresponds to a CD44v with the inclusion of exon v10 (30). The result was also identified at protein level by using a CD44v10-specific antibody (Fig. 2D). Therefore, the HA subpopulation of $\mathrm{BCa}$ was characterized by the preference to express the CD44v10 isoform.

Knockdown of the CD44v10 isoform increases the HA binding ability of $H A^{-/ l o w}$ binding subpopulation. Following the identification that CD44v10 was preferentially expressed in $\mathrm{HA}^{- \text {-low }}$ subpopulation, the effect of the CD44v10 isoform on the capacity of HA binding was further investigated. siRNA was used to knockdown the expression of CD44v10 in the $\mathrm{HA}^{- \text {-low }}$ binding subpopulation of MDA-MB-231 cells. As presented in Fig. 3A, the protein expression level of CD44v10 was markedly decreased in the $\mathrm{HA}^{- \text {-low }}$ subset of MDA-MB-231 cells after CD44v10 siRNA transfection. Subsequently, a flow cytometer 
A

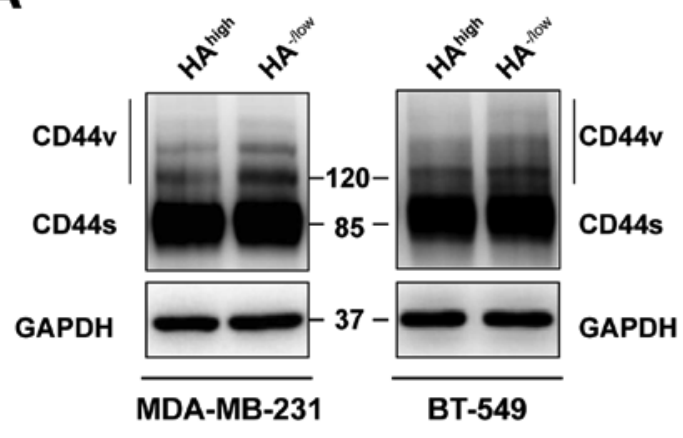

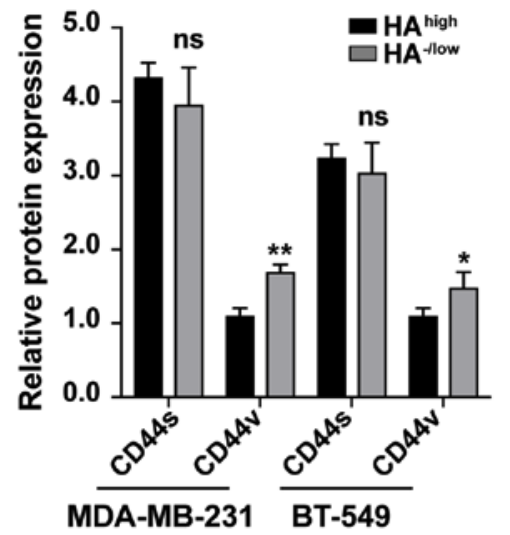

MDA-MB-231 BT-549

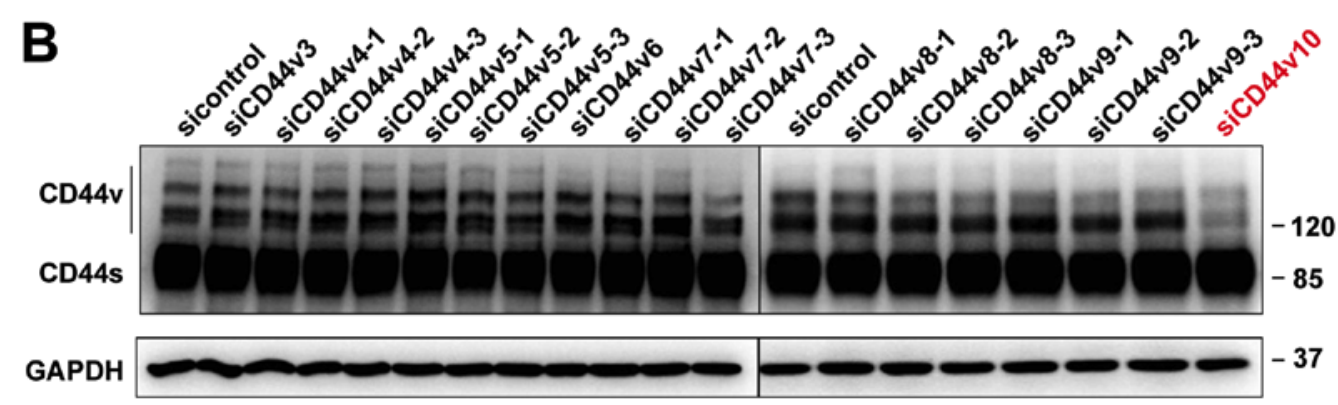

MDA-MB-231

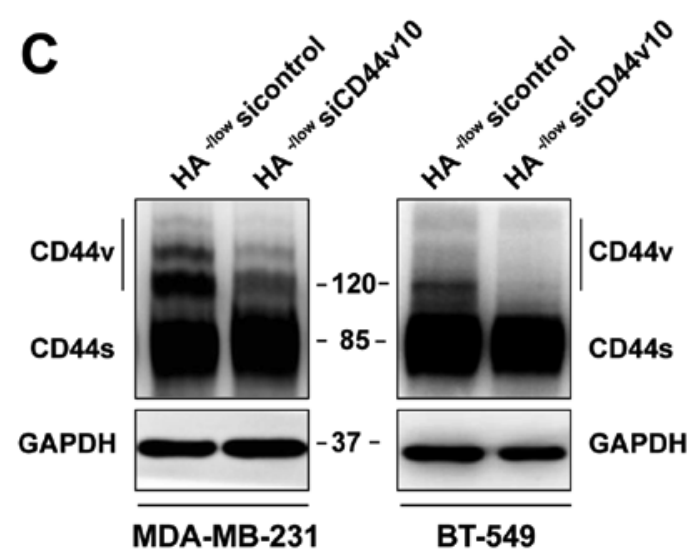

D

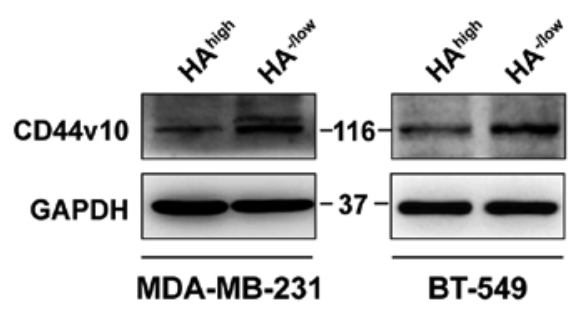

Figure 2. $\mathrm{CD} 44 \mathrm{v} 10$ isoform is highly expressed in the $\mathrm{HA}^{- \text {llow }}$ binding subpopulation. (A) Expression levels of different $\mathrm{CD} 44$ isoforms of sorted $\mathrm{HA} \mathrm{A}^{\text {high }}$ and $\mathrm{HA}^{-/ \text {low }}$ subpopulations in MDA-MB-231 and BT-549 cells. (B) Western blot analysis of CD44 isoforms in unsorted MDA-MB-231 cells after CD44v siRNAs transfection. (C) Protein expression levels of CD44 isoforms in sorted $\mathrm{HA}^{- \text {-low }}$ subsets after CD44v10 knockdown. (D) Expression of CD44v10 in sorted HA $\mathrm{A}^{\text {high }}$ and $\mathrm{HA}^{-/ \text {low }}$ cells from MDA-MB-231 and BT-549 cells. ${ }^{*} \mathrm{P}<0.05,{ }^{* *} \mathrm{P}<0.01$ vs. HA ${ }^{\text {high }}$ cells. HA, hyaluronan; siRNA/si, small interfering RNA; CD44v, CD44 variant; CD44s, CD44 standard; ns, no significance.

was used to evaluate the HA binding ability. As expected, HA binding was increased as compared with the sicontrol group following CD44v10 knockdown (Fig. 3B). Similar results were obtained in BT-549 cells, which also showed enhanced HA binding in CD44v10-silenced $\mathrm{HA}^{-/ \text {low }}$ subsets (Fig. 3C and D). Thus, CD44v10 could give rise to inhibition of HA binding.

Knockdown of the CD44v10 isoform inhibits the proliferation of $\mathrm{HA}^{\text {-llow }}$ binding subpopulation. Since CD44v10 was identified as the main cause differentiating between CD44-HA high and low interactions, the effect of the CD44v10 isoform on cell proliferation was examined. First, a CCK-8 assay was conducted to analyze the proliferative ability of cells after CD44v10 siRNA transfection. As indicated in Fig. 4A, knockdown of CD44v10 significantly suppressed the proliferation of $\mathrm{HA}^{-/ \text {low }}$ subsets in both MDA-MB-231 and BT-549 cells when compared with the sicontrol group. Similarly, the EdU incorporation assay and plate colony formation assay also confirmed the decreased proliferative ability of $\mathrm{HA}^{-/ \mathrm{low}}$ cells after CD44v10 knockdown (Fig. 4B and C).

To further verify whether the function of CD44v10 was mediated by HA binding capacity, CD44v10 was knocked down to enhance HA binding, in which an inhibited proliferation of $\mathrm{HA}^{-/ \mathrm{low}}$ cells was observed, while the proliferative capacity was rescued following the addition of an antibody to CD44 that blocks HA binding (Fig. 4D). Taken together, the aforementioned results demonstrated that knocking down CD44v10 could inhibit the proliferative and colony formation abilities of $\mathrm{HA}^{-/ \text {low }}$ binding subpopulations.

CD44v10 isoform facilitates the proliferation of BCa cell via the ERK/p38 MAPK and AKT/mTOR signaling pathways. 

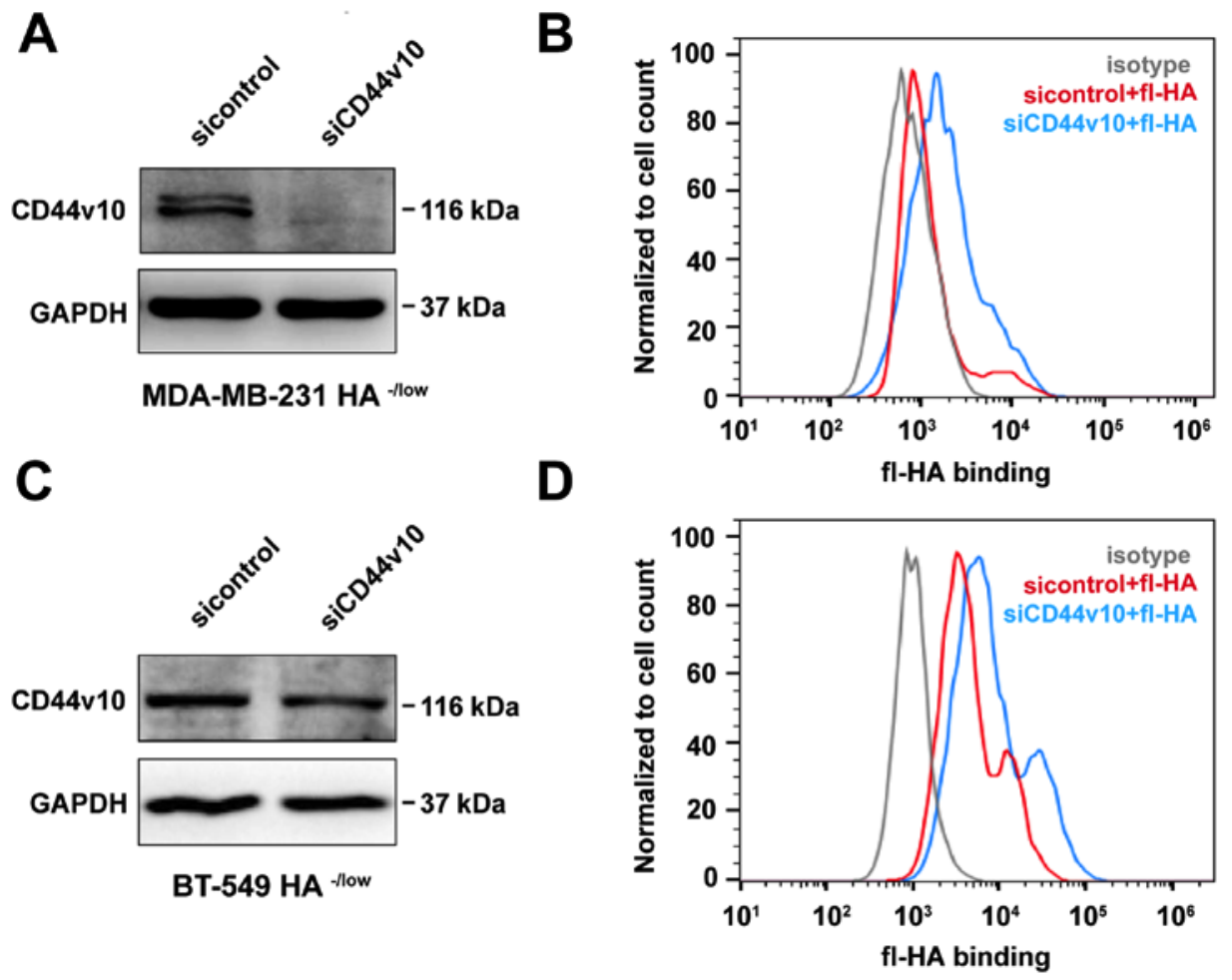

Figure 3. Knockdown of CD44v10 isoform increases the HA binding ability of $\mathrm{HA}^{-/ \mathrm{llow}}$ binding subpopulation. (A) Expression of CD44v10 in MDA-MB-231 $\mathrm{HA}^{-1 / \text { low }}$ cells transfected with CD44v10 siRNA. (B) Representative fl-HA binding profile of MDA-MB-231 HA ${ }^{-1 / \text { low }}$ subpopulation with control siRNA and CD44v10 siRNA transfection and re-exposure to fl-HA. The gray graph represents the isotype fluorescent level of unsorted cells without the addition of fl-HA. (C) Expression of CD44v10 in BT-549 $\mathrm{HA}^{- \text {/low }}$ cells transfected with CD44v10 siRNA. (D) Representative fl-HA binding profile of BT-549 HA-/low subpopulation with control siRNA and CD44v10 siRNA transfection and re-exposure to fl-HA. HA, hyaluronan; siRNA/si, small interfering RNA; CD44v, CD44 variant; fl, Fluorescein-labeled.

As the distinct CD44 active status mediated by CD44v10 displayed different proliferative capabilities, this study next sought to identify whether the expression levels of cell proliferation-related signaling molecules were altered. Previous studies have reported that ERK/p38 MAPK and AKT/mTOR signaling pathways are involved in the regulation of cell proliferation $(31,32)$. Thus, the expression levels of p-ERK, p-p38, p-AKT and p-mTOR were examined via western blotting. As presented in Fig. 5A, p-ERK expression was upregulated in $\mathrm{HA}^{-/ \mathrm{llw}}$ binding cells, while the expression of $\mathrm{p}-\mathrm{p} 38$ was slightly decreased. Similarly, both AKT and its downstream executor mTOR displayed elevated phosphorylation in $\mathrm{HA}^{-/ / \mathrm{low}}$ binding subpopulations (Fig. 5B). A high p-ERK to p-p38 ratio is regarded as an indicator of proliferating cells (33). Consistently, it was observed that the ratio of p-ERK to p-p38 was markedly increased in $\mathrm{HA}^{-/ \mathrm{low}}$ binding cells (Fig. 5C). Collectively, the expression levels of signaling molecules associated with proliferation were significantly higher in $\mathrm{HA}^{-/ l o w}$ cells compared with in $\mathrm{HA}^{\text {high }}$ subsets (Fig. 5C).

To evaluate the possible roles of ERK/p38 MAPK pathways in CD44v10-mediated proliferation, western blotting was conducted after knocking down CD44v10 in both MDA-MB-231 and BT-549 cells. The results demonstrated that the phosphorylation of ERK was significantly downregulated by CD44v10 knockdown, while the phosphorylation of p38 was not changed in $\mathrm{HA}^{-/ \text {low }}$ binding cells, as compared with the sicontrol group (Fig. 5D and E). Although the expression of p-p38 was not changed by silencing CD44v10, the ratio of p-ERK to p-p38 was significantly decreased (Fig. 5E).
To further investigate whether HA binding capacity mediated ERK/p38 MAPK activation, rescue experiments were performed. As presented in Fig. 5D and E, p-ERK expression rescued following the addition of an antibody to CD44 that blocked HA binding. Furthermore, a similar decreasing trend was observed for the alterations in p-AKT and p-mTOR levels induced by $\mathrm{CD} 44 \mathrm{v} 10$ knockdown in the $\mathrm{HA}^{-/ \mathrm{low}}$ binding subsets (Fig. 5F), while the phosphorylated levels were rescued following the addition of an antibody to CD44 that blocked HA binding (Fig. 5F and G). Taken together, these results suggested that the CD44v10 isoform facilitated the proliferation of $\mathrm{BCa}$ cells via ERK/p38 MAPK and AKT/mTOR activation.

\section{Discussion}

CD44 has long been recognized as a cell surface receptor that mediates diverse biological functions. As previously suggested, CD44 exists in two distinct states: It is in a resting state on the surface of most normal cells, while it becomes active following an inflammatory stimulus $(34,35)$. A feature for the 'activated' stage of CD44 is that it can bind to its ligand HA (36). Usually, tumor-derived cells often express CD44 in an active state that can bind and internalize to HA (37). Although CD44 expression has been reported to be closely associated with tumor malignancies, few studies have examined whether CD44 activation is critical for cancer development (38). The present study demonstrated a potential association between the activation status of CD44 and its subsequent effect on $\mathrm{BCa}$ cell proliferation. The current results indicated that $\mathrm{BCa}$ 
A

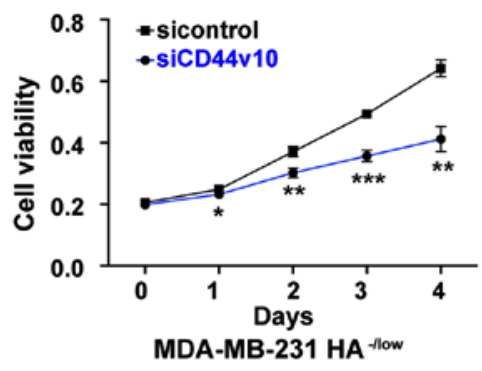

B

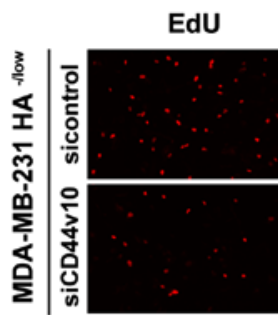

EdU

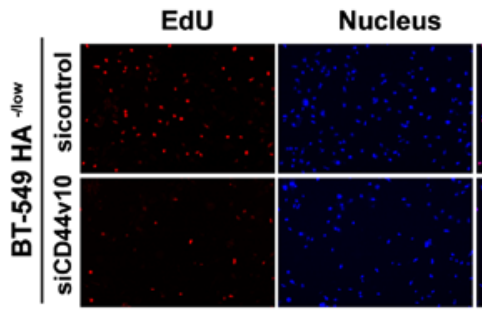

C

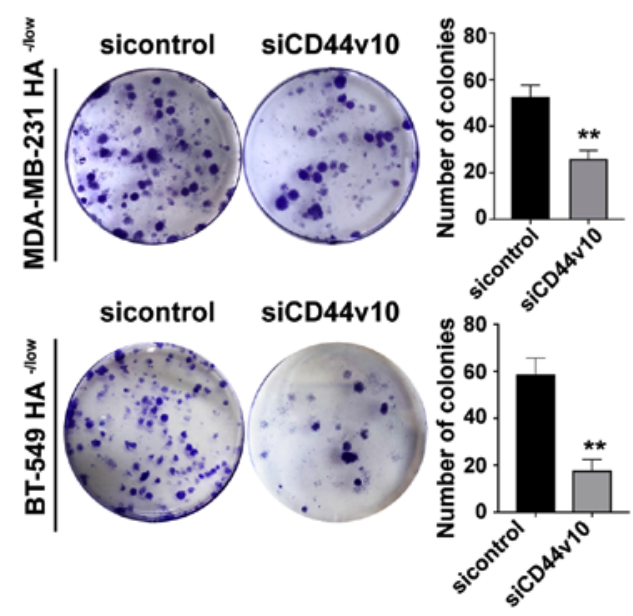

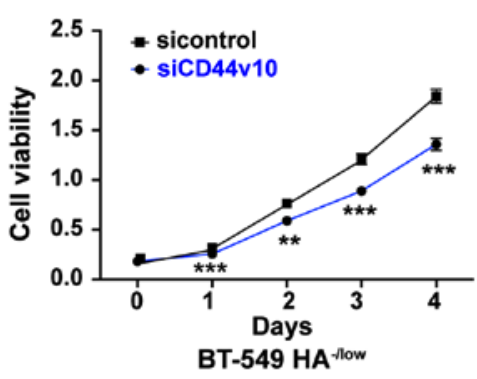

Nucleus Merged

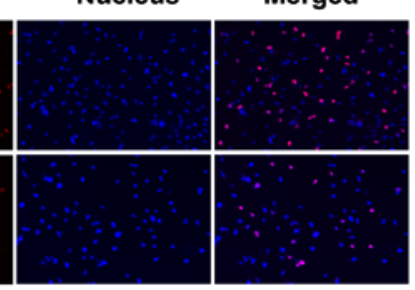

Merged
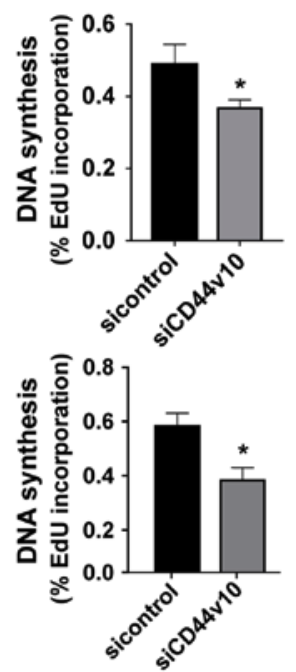

D

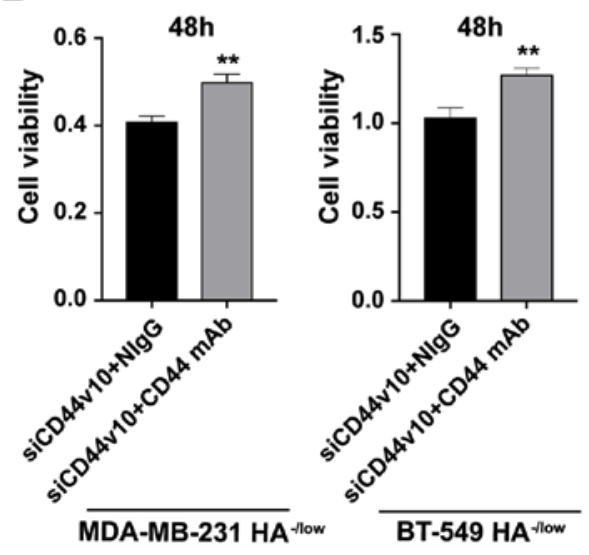

Figure 4. Knockdown of CD44v10 isoform inhibits the proliferation of $\mathrm{HA}^{-/ \text {low }}$ binding subpopulation. (A) Cell proliferation was evaluated using a CCK-8 assay after CD44v10 knockdown. (B) Cell proliferation was also assessed using the EdU incorporation assay (magnification, $\mathrm{x} 100)$. (C) Proliferative ability of $\mathrm{HA}^{-/ / \mathrm{low}}$ cells transfected with CD44v10 was detected by colony formation. ${ }^{*} \mathrm{P}<0.05,{ }^{* *} \mathrm{P}<0.01,{ }^{* * *} \mathrm{P}<0.001$ vs. sicontrol group. (D) Viability of MDA-MB-231 and BT-549 $\mathrm{HA}^{-/ \text {low }}$ cells after control siRNA or CD44v10 siRNA transfection and treatment with anti-CD44 mAb or NIgG (10 $\left.\mu \mathrm{g} / \mathrm{ml}\right)$ for $48 \mathrm{~h}$ was measured using a CCK-8 assay. Unpaired Student's t-tests were used to analyze the data. Data are presented the mean \pm SD of three experiments; $\mathrm{n}=3$. ${ }^{* *} \mathrm{P}<0.01 \mathrm{vs}$. siCD44v10 $+\mathrm{NIgG}$ group. NIgG, normal mouse IgG; CCK, Cell Counting Kit; HA, hyaluronan; siRNA/si, small interfering RNA; CD44v, CD44 variant; EdU, 5-ethynyl-2'-deoxyuridine; mAb, monoclonal antibody.

cells with inactive CD44 states had higher proliferation, while the subsets with active CD44 grew slowly. However, these findings are not consistent with some previous studies, which indicated CD44 activation was likely to support tumor growth. For example, evidence for CD44 activation giving rise to cell proliferation was provided for smooth muscle cells, fibroblasts, immune cells and endothelial cells (39). Moreover, a similar phenomenon was observed in melanoma cells (40) and mesothelioma cells (41). However, Veiseh et al (42) reported that a $\mathrm{HA}^{\text {low }}$ binding subpopulation sorted from BCa cells exhibited significantly higher proliferation compared with unsorted parental cells or the $\mathrm{HA}^{\text {high }}$ subpopulation, which was consistent with the present results. These studies implied that the recognition of CD44 on HA could either positively or negatively affect tumor growth. Such contradictory results may be ascribed to different types of cancer or different studies investigating various cell types. It is thus possible that CD44 activation is essential for tumor growth derived from certain organs, such as the skin (43) and lung (44), whereas tumors derived from other sources have no such requirement.

The present study first sorted resting and active CD44 expressing subpopulations from $\mathrm{BCa}$ cell lines according to their binding abilities to fl-HA. Then, western blotting results demonstrated that CD44s was highly expressed in both $\mathrm{HA}^{\text {high }}$ 

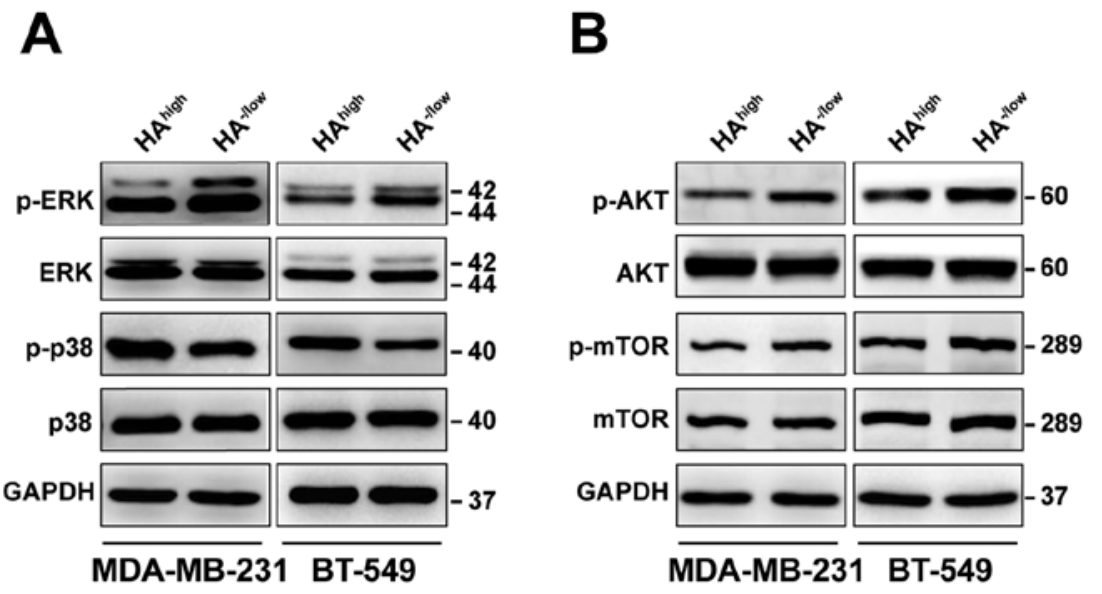

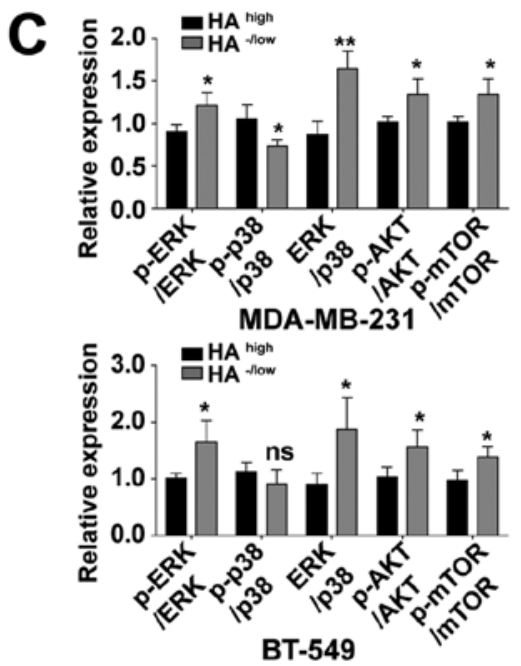

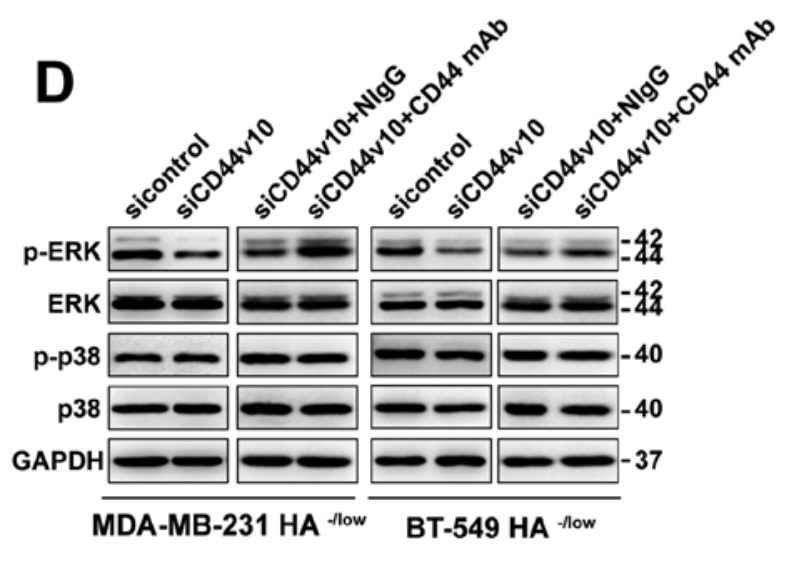
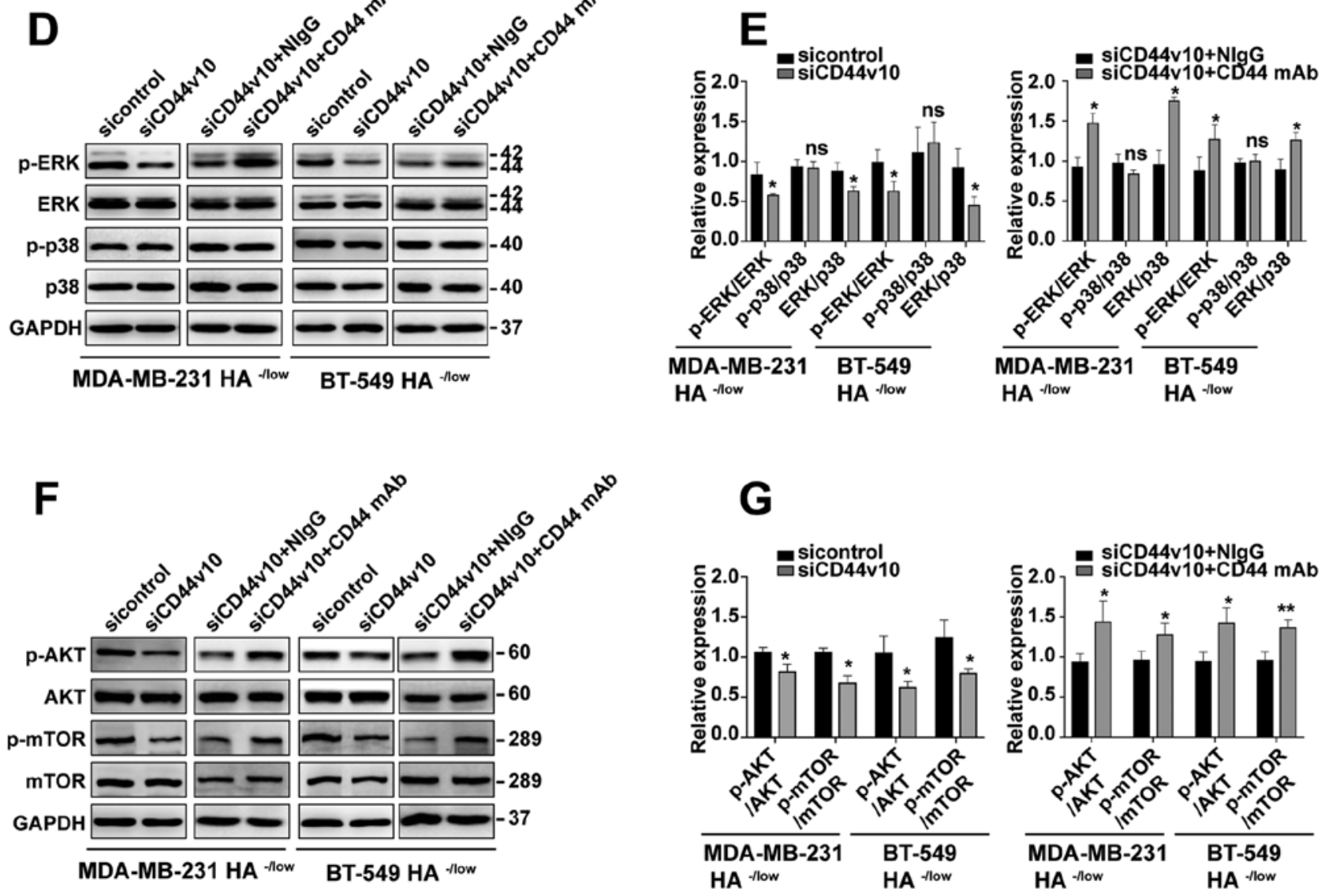

Figure 5. CD44v10 isoform facilitates the proliferation of BCa cells via the ERK/p38 MAPK and AKT/mTOR signaling pathways. Expression levels of (A) ERK/p38 MAPK and (B) AKT/mTOR signals in $\mathrm{HA}^{\text {high }}$ and $\mathrm{HA}^{\text {-/low }}$ subpopulations were examined via western blotting. (C) Relative protein expression of ERK/p38 MAPK and AKT/mTOR pathways in $\mathrm{HA}^{\text {high }}$ and $\mathrm{HA}^{-/ l o w}$ cells. ${ }^{*} \mathrm{P}<0.05,{ }^{* *} \mathrm{P}<0.01 \mathrm{vs}$. $\mathrm{HA}^{\text {high }}$. (D) Western blot analysis of ERK/p38 MAPK signals of MDA-MB-231 HA ${ }^{-/ \mathrm{low}}$ and BT-549 $\mathrm{HA}^{-/ \mathrm{low}}$ cells after CD44v10 knockdown. (E) Relative protein expression of ERK/p38 MAPK in HA ${ }^{-/ / \mathrm{lw}}$ cells transfected with CD44v10 siRNA. (F) Western blot analysis of AKT/mTOR signals of MDA-MB-231 HA $\mathrm{A}^{- \text {llow }}$ and BT-549 $\mathrm{HA}^{-/ \mathrm{low}}$ cells after CD44v10 knockdown. (G) Relative protein expression of AKT/mTOR in $\mathrm{HA}^{-/ 10 w}$ cells transfected with CD44v10 siRNA. Unpaired Student's t-tests were used to analyze the data. "P<0.05, ${ }^{* *} \mathrm{P}<0.01$ vs. sicontrol group or siCD44v10 + NIgG group. HA, hyaluronan; siRNA/si, small interfering RNA; CD44v, CD44 variant; CD44s, CD44 standard; ns, no significance; p-, phosphorylated; $\mathrm{NIgG}$, normal mouse IgG; mAb, monoclonal antibody.

and $\mathrm{HA}^{-/ \mathrm{low}}$ subsets without obvious difference. However, the expression of CD44v was significantly higher in $\mathrm{HA}^{-/ \mathrm{low}}$ cells. This unique finding suggested that CD44v may have an essential role in regulating CD44 activities in BCa cells. Previous studies have revealed that elevated levels of CD44 do not necessarily correlate with increased HA-binding, while the binding capacities differ in various CD44 isoforms $(45,46)$. Some reports suggested that CD44s binds to HA more efficiently compared with CD44v8-v10 $(21,47)$, whereas another study observed that CD44v4-v7 had a stronger HA-binding capacity compared with CD44s (22). Although these inconsistencies are still being investigated, different isoforms of CD44 subtypes or variants coexisting within the same cell population are considered to be responsible for such CD44-HA binding affinity heterogeneity. 


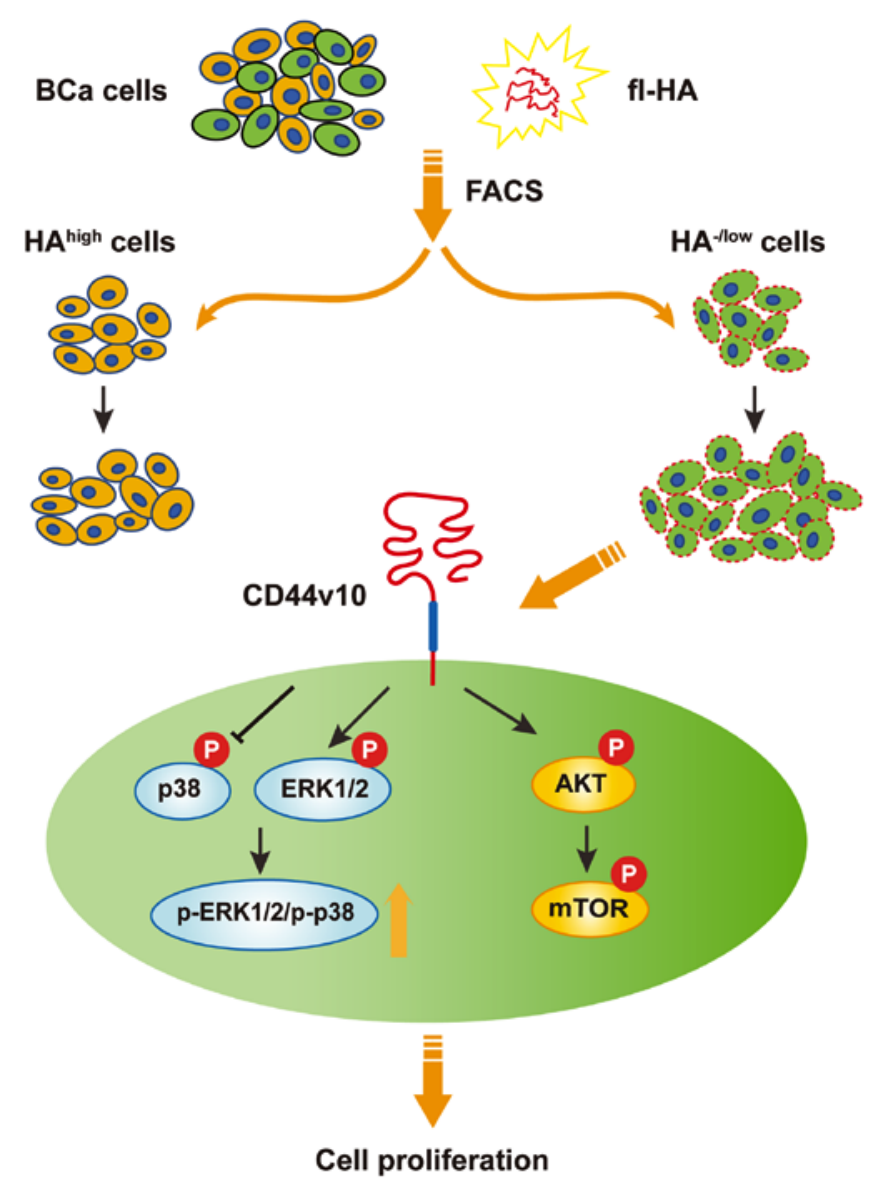

Figure 6. A schematic diagram of potential regulation by $\mathrm{CD} 44 \mathrm{v} 10$ on $\mathrm{BCa}$ cell proliferation. A CD44 activation model shows a phenotypic distinction between two subpopulations: $\mathrm{BCa}$ cells with inactive CD44 status ( $\left.\mathrm{HA}^{-/ / \mathrm{low}}\right)$ had higher proliferation and the subsets with active CD44 (HA ${ }^{\text {high }}$ ) grew slowly. The $\mathrm{HA}^{-/ \mathrm{low}}$ cell preferentially expressed $\mathrm{CD} 44 \mathrm{v} 10$ isoform (red dashed membrane). $\mathrm{CD} 44 \mathrm{v} 10$ isoform probably facilitates $\mathrm{BCa}$ cell proliferation via regulating the p-ERK1/2-to-p-p38 ratio and AKT/mTOR signaling pathway. p-, phosphorylated; HA, hyaluronan; fl, Fluorescein-labeled; CD44v, CD44 variant; $\mathrm{BCa}$, breast cancer.

In the present study, a panel of siRNAs targeting each CD44v exon region was designed and synthesized to identify the CD44v isoform that may determine the CD44-HA binding difference or CD44 activities. As expected, it was found that the differential expression band between $\mathrm{HA}^{\text {high }}$ and $\mathrm{HA}^{-/ l o w}$ subpopulations was downregulated only by transfection with CD44v10 siRNA, inferring that CD44v10 was responsible for distinct $\mathrm{HA}$ binding abilities between the two subsets. To further verify the effect of CD44v10 on HA binding, CD44v10 expression was knocked down by transfecting CD44v10 siRNA in $\mathrm{HA}^{-/ \text {low }}$ cells. It was found that the HA binding ability was enhanced after knocking down CD44v10 expression. The present findings were in line with previous reports, which suggested that post-translational modifications of CD44v10 induced surface rearrangements and conformational changes in the HA binding domains, finally leading to a loss of HA binding (48-50).

Even though the upregulation of several CD44v isoforms has been reported to be associated with $\mathrm{BCa}$ progression and prognosis (51), so far, only a few studies have revealed the function of the CD44v10 isoform in BCa. As previously suggested, CD44v10 is highly expressed in various cancer types, such as Hodgkin's disease (52), multiple myeloma (53), lymphoma (54) and renal cell carcinoma (55), and is associated with an unfavorable clinical outcome. In the present study, it was identified that CD44v10 was highly expressed in the $\mathrm{HA}^{-/ \text {low }}$ binding subset, which exhibited a stronger proliferation capability compared with the $\mathrm{HA}^{\text {high }}$ cells. Furthermore, knockdown of CD44v10 markedly inhibited the proliferative capability and colony formation ability of $\mathrm{HA}^{-/ l o w}$ binding subpopulation. The loss- and gain-of-function experiments indicated that the enhanced HA binding ability by CD44v10 siRNA transfection significantly inhibited the proliferation of $\mathrm{HA}^{- \text {/low }}$ cells. At the same time, the proliferative capacity could be rescued by the addition of an antibody to CD44 that specifically blocks HA binding. Collectively, these data suggested that CD44v10 mediated by CD44 activities has a key role in $\mathrm{BCa}$ cells proliferation.

To further understand the intracellular mechanism via which CD44v10 enhances BCa cell proliferation, the present study next investigated the effect of CD44v10 on cell proliferation-related signaling molecules. CD44 isoforms can promote $\mathrm{BC}$ a cell proliferation and survival by activation of two important members of MAPK families, including ERK1/2 and p38, as well as the AKT/mTOR signaling pathway $(25,56)$. In the current research, it was demonstrated that phosphorylation of ERK1/2, AKT and mTOR was elevated in $\mathrm{HA}^{-/ \text {low }}$ binding cells and was subsequently downregulated by knockdown of CD44v10. Conversely, the expression of p-p38 was slightly lower in $\mathrm{HA}^{- \text {-low }}$ binding subpopulations, and knockdown CD44v10 in $\mathrm{HA}^{-/ \text {low }}$ cells showed no effect on $\mathrm{p} 38$ phosphorylation. As previously reported, although ERK was mostly involved in the induction of proliferation, a high level of p38 activity was considered to be a negative growth regulator that may suppress cell proliferation by inhibiting ERK (57-59). Accordingly, a high ERK-to-p38 ratio dictated cell proliferation, while a low ERK-to-p38 predicted cell proliferation arrest and dormancy (33). In the present study, although the phosphorylation of p38 decreased or unchanged, the ratio of ERK-to-p38 phosphorylation was significantly higher in $\mathrm{HA}^{\text {-llow }}$ subsets compared with in $\mathrm{HA}^{\text {high }}$ cells, and the ratio was decreased in $\mathrm{HA}^{-/ \mathrm{low}}$ subsets after silencing CD44v10. These results suggested that ERK/p38 MAPK signals are likely to be involved in CD44v10-induced proliferation. Additionally, the rescue experiments indicated that the phosphorylation ERK/p38 and AKT/mTOR could be rescued following the addition of an antibody to CD44 that blocks HA binding. Overall, the present study demonstrated that CD44v10 regulated by CD44 activities could enhance the proliferation of BCa cells by triggering the ERK/p38 MAPK and AKT/mTOR signaling pathway cascades.

In summary, the present study demonstrated that the biological function was distinct between inactive and active CD44 status in BCa cells, and the CD44v10 isoform was responsible for the CD44 activities (Fig. 6). It was suggested that CD44v10 may facilitate proliferation via the activation of the ERK/p38 MAPK and AKT/mTOR signaling pathways. Collectively, this study provided novel insight into the mechanisms underlying CD44 activation and suggested that CD44v10 may be a potential therapeutic target for BCa. However, it remains unknown whether CD44v10 could facilitate tumor growth in vivo, thus further studies on the clinical significance of CD44v10 are 
warranted. Further work in this area is ongoing in the authors' laboratory.

\section{Acknowledgements}

Not applicable.

\section{Funding}

This work was funded by grants from the National Natural Science Foundation of China (grant nos. 81672843, 81702852, 81872357, 81974445, 81974446 and 82073199), Shanghai Municipal Education Commission-Gaofeng Clinical Medicine Grant Support (grant no. 20171924), Doctor Innovation Fund of Shanghai Jiaotong University School of Medicine (grant no. BXJ201944), Shanghai Pujiang Program (grant no. 2019PJD037) and Shanghai 'Rising Stars of Medical Talent' Youth Development Program Clinical Laboratory Practitioners Program (grant no. 2020087).

\section{Availability of data and materials}

The datasets used during the present study are available from the corresponding author upon reasonable request.

\section{Authors' contributions}

QG, CY and FG conceived and designed the study. QG, YL, YH, YD and GZ performed the experiments and analyzed the data. QG wrote the draft manuscript. CY and FG supervised the study and revised the manuscript. All authors read and approved the manuscript.

\section{Ethics approval and consent to participate}

Not applicable.

\section{Patient consent for publication}

Not applicable.

\section{Competing interests}

The authors declared that they no competing interests.

\section{References}

1. Bray F, Ferlay J, Soerjomataram I, Siegel RL, Torre LA and Jemal A: Global cancer statistics 2018: GLOBOCAN estimates of incidence and mortality worldwide for 36 cancers in 185 countries. CA Cancer J Clin 68: 394-424, 2018.

2. Yeo SK and Guan JL: Breast cancer: Multiple subtypes within a tumor? Trends Cancer 3: 753-760, 2017.

3. Heldin P, Basu K, Kozlova I and Porsch H: HAS2 and CD44 in breast tumorigenesis. Adv Cancer Res 123: 211-229, 2014.

4. Senbanjo LT and Chellaiah MA: CD44: A multifunctional cell surface adhesion receptor is a regulator of progression and metastasis of cancer cells. Front Cell Dev Biol 5: 18, 2017.

5. DeGrendele HC, Estess $P$ and Siegelman MH: Requirement for CD44 in activated T cell extravasation into an inflammatory site. Science 278: 672-675, 1997.

6. Chanmee T, Ontong P and Itano N: Hyaluronan: A modulator of the tumor microenvironment. Cancer Lett 375: 20-30, 2016.

7. Toole BP: Hyaluronan-CD44 interactions in cancer: Paradoxes and possibilities. Clin Cancer Res 15: 7462-7468, 2009.
8. Karousou E, Misra S, Ghatak S, Dobra K, Götte M, Vigetti D, Passi A, Karamanos NK and Skandalis SS: Roles and targeting of the HAS/hyaluronan/CD44 molecular system in cancer. Matrix Biol 59: 3-22, 2017.

9. McDonald B and Kubes P: Interactions between CD44 and hyaluronan in leukocyte trafficking. Front Immunol 6: 68, 2015.

10. Lesley J, Kincade PW and Hyman R: Antibody-induced activation of the hyaluronan receptor function of CD44 requires multivalent binding by antibody. Eur J Immunol 23: 1902-1909, 1993.

11. Ogino S,NishidaN,Umemoto R,Suzuki M,Takeda M, TerasawaH, Kitayama J, Matsumoto M, Hayasaka H, Miyasaka M, et al: Two-state conformations in the hyaluronan-binding domain regulate CD44 adhesiveness under flow condition. Structure 18: 649-656, 2010.

12. Lesley $\mathbf{J}$ and Hyman R: CD44 can be activated to function as an hyaluronic acid receptor in normal murine T cells. Eur J Immunol 22: 2719-2723, 1992.

13. Hiraga T, Ito $\mathrm{S}$ and Nakamura $\mathrm{H}$ : Cancer stem-like cell marker CD44 promotes bone metastases by enhancing tumorigenicity, cell motility, and hyaluronan production. Cancer Res 73: 4112-4122, 2013.

14. Hu S, Cao M, He Y, Zhang G, Liu Y, Du Y, Yang C and Gao F: CD44v6 targeted by miR-193b-5p in the coding region Modulates the migration and invasion of breast cancer cells. J Cancer 11: 260-271, 2020.

15. Zhao P, Xu Y, Wei Y, Qiu Q, Chew TL, Kang Y and Cheng C: The CD44s splice isoform is a central mediator for invadopodia activity. J Cell Sci 129: 1355-1365, 2016.

16. Teriete P,BanerjiS,Noble M,BlundellCD,Wright AJ,PickfordAR, Lowe E, Mahoney DJ, Tammi MI, Kahmann JD, et al: Structure of the regulatory hyaluronan binding domain in the inflammatory leukocyte homing receptor CD44. Mol Cell 13: 483-496, 2004.

17. Liu D, Liu T, Li R and Sy MS: Mechanisms regulating the binding activity of CD44 to hyaluronic acid.Front Biosci 3: d631-d636, 1998.

18. Louderbough JM and Schroeder JA: Understanding the dual nature of CD44 in breast cancer progression. Mol Cancer Res 9: 1573-1586, 2011.

19. Naor D, Nedvetzki S, Golan I, Melnik L and Faitelson Y: CD44 in cancer. Crit Rev Clin Lab Sci 39: 527-579, 2002.

20. Dougherty GJ, Cooper DL, Memory JF and Chiu RK: Ligand binding specificity of alternatively spliced CD44 isoforms. Recognition and binding of hyaluronan by CD44R1. J Biol Chem 269: 9074-9078, 1994.

21. Bennett KL, Modrell B, Greenfield B, Bartolazzi A, Stamenkovic I, Peach R, Jackson DG, Spring F and Aruffo A: Regulation of CD44 binding to hyaluronan by glycosylation of variably spliced exons. J Cell Biol 131: 1623-1633, 1995.

22. Sleeman J, Rudy W, Hofmann M, Moll J, Herrlich P and Ponta H: Regulated clustering of variant CD44 proteins increases their hyaluronate binding capacity. J Cell Biol 135: 1139-1150, 1996.

23. Orian-Rousseau V: CD44 Acts as a signaling platform controlling tumor progression and metastasis. Front Immunol 6: 154, 2015.

24. Chen C, Zhao S, Karnad A and Freeman JW: The biology and role of CD44 in cancer progression: Therapeutic implications. J Hematol Oncol 11: 64, 2018.

25. Liu S and Cheng C: Akt Signaling is sustained by a CD44 splice isoform-mediated positive feedback loop. Cancer Res 77: 3791-3801, 2017.

26. Yang C, Cao M, Liu H, He Y, Xu J, Du Y, Liu Y, Wang W, Cui L, Hu J, et al: The high and low molecular weight forms of hyaluronan have distinct effects on CD44 clustering. J Biol Chem 287: 43094-43107, 2012.

27. Zhang H, Brown RL, Wei Y, Zhao P, Liu S, Liu X, Deng Y, $\mathrm{Hu} \mathrm{X}$, Zhang J, Gao XD, et al: CD44 splice isoform switching determines breast cancer stem cell state. Genes Dev 33: 166-179, 2019.

28. Hu J, Li G, Zhang P, Zhuang X and Hu G: A CD44v' ${ }^{+}$subpopulation of breast cancer stem-like cells with enhanced lung metastasis capacity. Cell Death Dis 8: e2679, 2017.

29. Livak KJ and Schmittgen TD: Analysis of relative gene expression data using real-time quantitative PCR and the 2(-Delta Delta C(T)) method. Methods 25: 402-408, 2001.

30. Lokeshwar VB, Iida $\mathrm{N}$ and Bourguignon LY: The cell adhesion molecule, GP116, is a new CD44 variant (ex14/v10) involved in hyaluronic acid binding and endothelial cell proliferation. J Biol Chem 271: 23853-23864, 1996.

31. Aguirre-Ghiso JA,Estrada Y,Liu D and OssowskiL:ERK(MAPK) activity as a determinant of tumor growth and dormancy; regulation by p38(SAPK). Cancer Res 63: 1684-1695, 2003. 
32. Nan H, Han L, Ma J, Yang C, Su R and He J: STX3 represses the stability of the tumor suppressor PTEN to activate the PI3K-Akt-mTOR signaling and promotes the growth of breast cancer cells. Biochim Biophys Acta Mol Basis Dis 1864: 1684-1692, 2018.

33. Aguirre-Ghiso JA, Ossowski L and Rosenbaum SK: Green fluorescent protein tagging of extracellular signal-regulated kinase and p38 pathways reveals novel dynamics of pathway activation during primary and metastatic growth. Cancer Res 64 7336-7345, 2004.

34. Dong Y, Poon GF, Arif AA, Lee-Sayer SS, Dosanjh M and JohnsonP: The survival of fetal and bone marrow monocyte-derived alveolar macrophages is promoted by CD44 and its interaction with hyaluronan. Mucosal Immunol 11: 601-614, 2018.

35. Levesque MC and Haynes BF: Cytokine induction of the ability of human monocyte CD44 to bind hyaluronan is mediated primarily by TNF-alpha and is inhibited by IL-4 and IL-13. J Immunol 159: 6184-6194, 1997.

36. Siegelman MH, DeGrendele HC and Estess P: Activation and interaction of CD44 and hyaluronan in immunological systems. J Leukoc Biol 66: 315-321, 1999.

37. Bachar G, Cohen K, Hod R, Feinmesser R, Mizrachi A, Shpitzer T, Katz $\mathrm{O}$ and Peer D: Hyaluronan-grafted particle clusters loaded with Mitomycin $\mathrm{C}$ as selective nanovectors for primary head and neck cancers. Biomaterials 32: 4840-4848, 2011

38. Patrawala L, Calhoun T, Schneider-Broussard R, Li H, Bhatia B, Tang S, Reilly JG, Chandra D, Zhou J, Claypool K, et al: Highly purified CD $44^{+}$prostate cancer cells from xenograft human tumors are enriched in tumorigenic and metastatic progenitor cells. Oncogene 25: 1696-1708, 2006

39. Misra S, Hascall VC, Markwald RR and Ghatak S: Interactions between hyaluronan and its receptors (CD44, RHAMM) regulate the activities of inflammation and cancer. Front Immunol 6: 201, 2015.

40. Bartolazzi A, Peach R, Aruffo A and Stamenkovic I: Interaction between CD44 and hyaluronate is directly implicated in the regulation of tumor development. J Exp Med 180: 53-66, 1994.

41. Hanagiri T, Shinohara S, Takenaka M, Shigematsu Y, Yasuda M Shimokawa H, Nagata Y, Nakagawa M, Uramoto H, So T, et al: Effects of hyaluronic acid and CD44 interaction on the proliferation and invasiveness of malignant pleural mesothelioma. Tumour Biol 33: 2135-2141, 2012.

42. Veiseh M, Kwon DH, Borowsky AD, Tolg C, Leong HS, Lewis JD, Turley EA and Bissell MJ: Cellular heterogeneity profiling by hyaluronan probes reveals an invasive but slow-growing breast tumor subset. Proc Natl Acad Sci USA 111: E1731-E1739, 2014

43. Ahrens T, Sleeman JP, Schempp CM, Howells N, Hofmann M, Ponta H, Herrlich P and Simon JC: Soluble CD44 inhibits melanoma tumor growth by blocking cell surface CD44 binding to hyaluronic acid. Oncogene 20: 3399-3408, 2001.

44. Song JM, Im J, Nho RS, Han YH, Upadhyaya P and Kassie F: Hyaluronan-CD44/RHAMM interaction-dependent cell proliferation and survival in lung cancer cells. Mol Carcinog 58 321-333, 2019

45. Peach RJ, Hollenbaugh D, Stamenkovic I and Aruffo A: Identification of hyaluronic acid binding sites in the extracellular domain of CD44. J Cell Biol 122: 257-264, 1993.
46. Stamenkovic I, Aruffo A, Amiot M and Seed B: The hematopoietic and epithelial forms of CD44 are distinct polypeptides with different adhesion potentials for hyaluronate-bearing cells. EMBO J 10: 343-348, 1991

47. van der Voort R, Manten-Horst E, Smit L, Ostermann E, van den Berg F and Pals ST: Binding of cell-surface expressed CD44 to hyaluronate is dependent on splicing and cell type. Biochem Biophys Res Commun 214: 137-144, 1995.

48. Weimann TK, Wagner C, Funk R, Hirche H, Goos M and Wagner SN: Hyaluronan-independent adhesion of $\mathrm{CD} 44 \mathrm{H}^{+}$and CD44v10+ lymphocytes to dermal microvascular endothelial cells and keratinocytes. J Invest Dermatol 117: 949-957, 2001.

49. Iida N and Bourguignon LY: Coexpression of CD44 variant (v10/ex14) and CD44S in human mammary epithelial cells promotes tumorigenesis. J Cell Physiol 171: 152-160, 1997.

50. Katoh S, Zheng Z, Oritani K, Shimozato T and Kincade PW Glycosylation of CD44 negatively regulates its recognition of hyaluronan. J Exp Med 182: 419-429, 1995.

51. Bellerby R, Smith C, Kyme S, Gee J, Günthert U, Green A, Rakha E, Barrett-Lee P and Hiscox S: Overexpression of specific CD44 isoforms is associated with aggressive cell features in acquired endocrine resistance. Front Oncol 6: 145, 2016.

52. Beham-Schmid C, Heider KH, Hoefler G and Zatloukal K: Expression of CD44 splice variant v10 in Hodgkin's disease is associated with aggressive behaviour and high risk of relapse. J Pathol 186: 383-389, 1998.

53. Asosingh K, Günthert U, De Raeve H, Van Riet I, Van Camp B and Vanderkerken $\mathrm{K}$ : A unique pathway in the homing of murine multiple myeloma cells: CD44v10 mediates binding to bone marrow endothelium. Cancer Res 61: 2862-2865, 2001.

54. Megaptche AP,ErbU,Büchler MW and Zöller M: CD44v10, osteopontin and lymphoma growth retardation by a CD44v10-specific antibody. Immunol Cell Biol 92: 709-720, 2014.

55. Li N, Tsuji M, Kanda K, Murakami Y, Kanayama H and Kagawa S: Analysis of CD44 isoform v10 expression and its prognostic value in renal cell carcinoma. BJU Int 85: 514-518, 2000.

56. Ishimoto $T$, Nagano $O$, Yae $T$, Tamada $M$, Motohara $T$, Oshima H, Oshima M, Ikeda T, Asaba R, Yagi H, et al: CD44 variant regulates redox status in cancer cells by stabilizing the $\mathrm{xCT}$ subunit of system $\mathrm{xc}(-)$ and thereby promotes tumor growth. Cancer Cell 19: 387-400, 2011.

57. Black EJ, Clark W and Gillespie DA: Transient deactivation of ERK signalling is sufficient for stable entry into G0 in primary avian fibroblasts. Curr Biol 10: 1119-1122, 2000.

58. Chen G, Hitomi M, Han J and Stacey DW: The p38 pathway provides negative feedback for Ras proliferative signaling. J Biol Chem 275: 38973-38980, 2000.

59. Aguirre-Ghiso JA, Liu D, Mignatti A, Kovalski K and Ossowski L: Urokinase receptor and fibronectin regulate the ERK(MAPK) to p38(MAPK) activity ratios that determine carcinoma cell proliferation or dormancy in vivo. Mol Biol Cell 12: 863-879, 2001.

This work is licensed under a Creative Commons Attribution-NonCommercial-NoDerivatives 4.0 International (CC BY-NC-ND 4.0) License. 